\title{
Inulin attenuates atherosclerosis in apolipoprotein E-deficient mice
}

\author{
Marie-Hélène Rault-Nania ${ }^{1}$, Elyett Gueux ${ }^{1}$, Céline Demougeot $^{2}$, Christian Demigné $^{1}$, Edmond Rock $^{1}$ and \\ Andrzej Mazur ${ }^{1 *}$ \\ ${ }^{1}$ Equipe Stress Métabolique et Micronutriments, Unité de Nutrition Humaine UMR1019, INRA, Theix, Centre de Recherche en \\ Nutrition Humaine d'Auvergne, 63122 Saint-Genès-Champanelle, France \\ ${ }^{2}$ Laboratoire de Physiologie et Pharmacologie - Nutrition Préventive Expérimentale, Faculté de Médecine et de Pharmacie, \\ Besançon, France
}

(Received 2 February 2006 - Revised 9 June 2006 - Accepted 12 June 2006)

\begin{abstract}
Effects of different inulin-type fructan fractions were studied on atherosclerotic plaque formation in male apo E-deficient mice. Thirty-two mice were randomly divided into four groups and received either a semi-purified sucrose-based diet (control group), or diets in which sucrose was replaced in part by various inulin-type fructans $(10 \mathrm{~g} / 100 \mathrm{~g})$ : long-chain inulin, oligofructose, or an oligofructose-enriched inulin for 16 weeks. The presence of atherosclerotic plaques was assessed by histomorphometry in the aortic sinus. The apo E-deficient mice fed long-chain inulin or an oligofructose-enriched inulin had about $35 \%$ and $25 \%$ less atherosclerotic lesion area compared with the control group, respectively. Feeding long-chain inulin significantly reduced plasma cholesterol concentrations $(P<0 \cdot 001)$, and the three inulin-type fructans reduced triacylglycerol (TAG) concentrations compared with the control group $(P<0 \cdot 001)$. Both the long-chain inulin and an oligofructose-enriched inulin significantly lowered hepatic cholesterol concentrations compared with the control diet $(P<0 \cdot 05)$. Hepatic TAG concentrations were significantly lower in all three groups fed the fructan-supplemented diets $v$. the control group $(P<0.0001)$. The results of the present study suggest that inhibition of atherosclerotic plaque formation is more potent in the presence of long-chain inulin, either alone or in combination with oligofructose (an oligofructoseenriched inulin), and that this probably is related to changes in lipid metabolism.
\end{abstract}

Inulin: Oligofructose: Apolipoprotein E-deficient mice: Atherosclerosis

Atherosclerosis is an important risk factor of CVD (Charakida et al. 2006), which is one of the major causes of mortality in Western countries (Steinberg et al. 2003). Hyperlipidaemia, often associated with inappropriate food choices (Cordain et al. 2005), is well recognised as a risk factor for the development of atherosclerosis (Wouters et al. 2005). In order to promote the consumption of complex carbohydrates, which are naturally present in fruits and vegetables (Roberfroid, 2002), various food items are nowadays supplemented with these. In addition, inulin-type fructans can also be used as sugar and/or fat substitutes in a variety of food applications such as milk products, baked goods, fruit preparations and confectionery (Kaur \& Gupta, 2002). Inulintype fructans are non-digestible oligosaccharides made up of fructose monomers (some with a terminal glucose) and are classified as soluble dietary fibre (Cherbut, 2002). Previous studies in animals and human subjects have found a hypolipidaemic effect when inulin was supplemented to the diet (Beylot, 2005). However, inulin and oligofructose also have other effects that might contribute to the anti-atherogenic action. Busserolles et al. (2003) showed that oligofructose is protective against the pro-oxidative effects of fructose-rich diets in rats. In addition, endproducts of dietary fibre fermentation, such as SCFA, can modulate the expression of multiple genes involved in the process of atherosclerosis (Ranganna et al. 2000). Based on these data it can be hypothesised that the addition of inulin-type fructans to diets may reduce the atherosclerosis process, similar to the antiatherosclerotic effect described for some dietary fibres (Wu et al. 2003).

In the present study, we investigated the effects of different fractions of inulin-type fructans in an apo E-deficient atherosclerosis mouse model, which is widely used to study the atherogenic process (Meir \& Leitersdorf, 2004). The mouse model corresponds to familial dysbetalipoproteinaemia and the animals develop lesions even on a standard low-fat diet, the earliest lesions appearing in the aortic valve (Napoli et al. 2000). In the present study we assessed the anti-atherogenic effects of inulintype fructans with different degrees of polymerisation (DP), for example, oligofructose (short chain) and long-chain inulin. Shorter inulin-type chains are rapidly and selectively fermented by the colonic flora leading to a high increase in bifidobacteria in the proximal colon. Long-chain inulin is fermented at a lower rate, inducing its prebiotic effect towards the more distal (descending) parts of the colon (Roberfroid, 2005). The oligofructose-enriched inulin is a combination of both inulin types and

\footnotetext{
Abbreviations: DP, degree of polymerisation; TAG, triacylglycerol.

* Corresponding author: Dr Andrzej Mazur, fax +33 47362 4638, email mazur@clermont.inra.fr
} 
therefore it exerts a sustained prebiotic effect throughout the entire colon.

\section{Materials and methods}

\section{Animals and diets}

Pairs of homozygous apo E-deficient mice were provided by Jackson Laboratories (Charles River Laboratories, L'Arbresle, France). The males for the present study were obtained through interbreeding these homozygous mice at the Institute animal facility (Unité de Nutrition Expérimentale, INRA, Theix, France). They were housed in groups of four in wire-bottomed cages in a temperature-controlled room $\left(22 \pm 0.8^{\circ} \mathrm{C}\right)$ with a $12 \mathrm{~h}$ light-dark cycle and a relative humidity of $55 \pm 10 \%$. The mice were maintained and handled according to the recommendations of the INRA Ethics Committee - decree no. $87-848$. The mean body weight of mice at the start of the experiment was 20.5 (SE 0.5) g. All mice were fed a powdered purified diet, based on the AIN-93G recommendations, in which all carbohydrates were supplied as sucrose (Table 1). At 9 weeks of age, mice were divided into four groups (eight mice per group). One group received a sucrose-based diet (control group), and the three other groups received diets in which sucrose was substituted in part with various inulin-type fructans $(6.3 \%(\mathrm{w} / \mathrm{w})$ during the 3 -week adaptation period and $10 \%$ (w/w) during the following 13 weeks). Table 1 provides the composition of the diets (given as wt/wt \%). Food and distilled water were provided ad libitum. The inulin-type fructans studied $\left(\right.$ Beneo $^{\mathrm{TM}}$ ) were obtained from Orafti (a division of Raffinerie Tirlemontoise, Tienen, Belgium). Oligofructose (Beneo $^{\mathrm{TM}}$ P95) is obtained by partial enzymic hydrolysis of native inulin, extracted from the chicory root, with a DP ranging from 2 to 8 (average DP 4). Long-chain inulin (Beneo ${ }^{\mathrm{TM}} \mathrm{HP}$ ) is obtained from the physical removal of the lower-DP fraction present in native inulin and has a DP from 10 to 65 (average DP 25). Beneo ${ }^{\mathrm{TM}}$ Synergy1 is an oligofructose-enriched inulin and is made up of a mixture of oligofructose and longchain inulin.

Mice were examined for clinical appearance twice per week (when they were weighed and when the litter in the cages was changed). The systolic blood pressure was measured at the 15 th week by a tail-cuff method with a BP 2000 Blood Pressure Analysis System (Visitech System, Apex, NC, USA). The

Table 1. Formulation of the diets $†$

\begin{tabular}{lcc}
\hline Ingredient & Control & Inulin-type fructans* \\
\hline Sucrose (\%) & 63 & 53 \\
Inulin-type fructan (\%) & 0 & 10 \\
Casein (\%) & 20 & 20 \\
Maize oil (\%) & 7 & 7 \\
Cellulose (\%) & 5 & 5 \\
Mineral mix AIN-93 G (\%) & 3.5 & 3.5 \\
Vitamin mix AIN-93 G (\%) & 1 & 1 \\
L-Cystine (\%) & 0.3 & 0.3 \\
Choline bitartrate (\%) & 0.25 & 0.25 \\
tert-Butylhydroquinone (\%) & 0.0014 & 0.0014 \\
\hline
\end{tabular}

* The inulin-type fructans used were oligofructose, long-chain inulin or an oligofructose-enriched inulin.

†For details of diets and procedures, see p. 841 mice were trained for blood pressure measurements to reduce stress-inducible changes in this parameter and the presented results correspond to the third measurement.

At the end of the experiment, mice were killed under pentobarbital anaesthesia. Blood was collected from the abdominal aorta into heparinised tubes. Plasma was prepared by lowspeed centrifugation. The plasma samples were stored at $-80^{\circ} \mathrm{C}$. The organs were washed with heparinised physiological saline in the systemic pathway. The heart (with aorta) and the liver of each mouse were harvested in liquid $\mathrm{N}_{2}$ and stored at $-80^{\circ} \mathrm{C}$ until analysis. The whole caecum and the caecum contents were weighed individually for each mouse.

\section{Plasma and hepatic lipids}

Plasma total cholesterol and triacylglycerol (TAG) concentrations were measured using enzymic assays (Biomérieux, Marcy-l'Etoile, France) as described previously (Mazur et al. 1990). Liver samples were homogenised in $\mathrm{KCl}(9 \mathrm{~g} / \mathrm{l})$ with a Polytron homogeniser (Kinermatica $\mathrm{GmbH}$, Lucerne, Switzerland) and lipids were chloroform-methanol (2:1, v/v) extracted under overnight agitation. The chloroform phase was recovered after centrifugation and evaporated under dry air. TAG from the lipid residue were saponified with $0.5 \mathrm{M}-\mathrm{KOH}-$ ethanol at $70^{\circ} \mathrm{C}$ for $30 \mathrm{~min}$ followed by the addition of $0.15 \mathrm{M}$ $\mathrm{MgSO}_{4}$ to neutralise the mixture. After centrifugation (2000 g; $5 \mathrm{~min}$ ) the concentrations of glycerol in the supernatant fractions were determined. The cholesterol in the lipid residue was dissolved with isopropanol. Total cholesterol and TAG levels were determined by enzymic assay (Biomérieux). Absorbance at $492 \mathrm{~nm}$ was measured in a spectrophotometer (Uvikon 941 plus series; Kontron instruments, St Quentin en Yvelines, France). A control serum (Biomérieux) was processed in parallel to verify the accuracy of the plasma and tissue lipid analyses.

\section{Assessment of atherosclerosis}

Quantification of atherosclerotic lesions was done by calculating the lipid deposition size in the aortic sinus as previously described (Nicoletti et al. 1998). Briefly, the peripheral fat of the upper aorta was removed and the thoracic and abdominal aortas were discarded. The heart with the aortic arch was dissected under a stereo microscope and frozen (in liquid $\mathrm{N}_{2}$ ) in optimal cutting temperature embedding medium for serial cryo-sectioning covering $400 \mu \mathrm{m}$ of the aorta root. The heart (stored at $-80^{\circ} \mathrm{C}$ ) was cut in a microtome (Frigocut $2800 \mathrm{E}$; Reichert-Jung, Nussloch, Germany) at $-20^{\circ} \mathrm{C}$. Sections ( $10 \mu \mathrm{m}$ thick) were collected at every $100 \mu \mathrm{m}$ throughout the aortic sinus ( $300 \mu \mathrm{m}$ of the distal portion) and analysed. The distal portion of the aortic sinus was recognised by the three valve cusps that are the junction of the aorta and the heart. Cryostat sections were evaluated for fatty streak lesions after staining with Oil red $\mathrm{O}$ and counterstaining with haematoxylin. Each section was evaluated for Oil red $\mathrm{O}$ staining area by capturing images directly from a colour camera (Sony XC-71P CCD RGB, Kenmore, WA, USA) attached to an Olympus light microscope (Reichert-Jung Polyvar, Vienna, Austria) and displaying them on a RGB monitor by using Visilog software (Noesis, Crolles, France). Image analysis was carried out using the ImageJ free software (http://rsb.info.nih.gov/ij/). In order to reduce errors induced by sectioning angle, results were 
expressed as the percentage of the cross-sectional vessel area stained with Oil red $\mathrm{O}$.

\section{Statistical analysis}

Results are expressed as mean values with their standard errors. Data were analysed by one-way ANOVA coupled with the Student-Newman-Keuls multiple comparison test (GraphPad Instat; GraphPad Software Inc., San Diego, CA, USA), except for the analysis of the lesions areas for which we used a two-way ANOVA (studied group and the aortic section effect) (REGWG test; Statview; SAS Institute Inc., Cary, NC, USA). Differences were considered significant if $P<0.05$. The data were transformed when the SD between groups was significantly different.

\section{Results}

\section{Animals}

There were no significant differences in final body masses and in the relative liver mass among groups (Table 2). However, all fructan-fed groups had significantly heavier (about 2.5-3 times) caecal weight (whole caecum, caecum contents and caecum wall) when compared with the control group $(P<0.0001)$ (Table 2). The three fructan-enriched diets did not significantly modify the systolic blood pressure compared with the control diet after 15 weeks on the experimental diets (Table 2).

\section{Plasma and hepatic lipid concentrations}

As shown in Table 3, the apo E knockout mice showed marked hypercholesterolaemia (13.56 (SE 0.73 ) $\mathrm{mmol} / \mathrm{l}$ in the control diet-fed group). This is severe hypercholesterolaemia; the level is about seven times higher than in C57/B16J mice $(1.85 \mathrm{mmol} / \mathrm{l}$ data from Mouse Phenome Database; Jackson Laboratory, Bar Harbor, ME, USA; http://phenome.jax.org/pub-cgi/phenome/ mpdcgi?rtn=docs/home). Feeding the mice inulin significantly lowered plasma total cholesterol concentrations compared with the control diet-fed group. Oligofructose and Synergy 1 had no significant effect on the plasma cholesterol when compared with the controls $(P<0 \cdot 001)$. Plasma TAG concentrations were significantly lower both in the inulin and oligofructose groups compared with the control group $(P<0 \cdot 01)$ (Table 3$)$.

Supplementing the diet with inulin and Synergy1 significantly lowered hepatic cholesterol concentrations compared with the control diet $(P<0 \cdot 05)$. This effect was not significantly different for the oligofructose group. All three groups fed the fructan-enriched diets presented an approximately 2fold reduction in hepatic TAG concentrations when compared with the control group $(P<0 \cdot 0001)$ (Table 3$)$.

\section{Atherosclerotic lesions in the aortic sinus}

The two-way ANOVA analysis indicated that there was both an effect of the diet and the aortic section $(P<0.0004)$, but there was no interaction between diet and aortic section $(P>0.05)$. The REGWQ test (Statview; SAS Institute Inc.) showed that the percentage lesion area in the mice fed inulin was significantly lower compared with both the control and the oligofructose-fed groups $(P<0 \cdot 01)$. Furthermore, in the rats fed Synergy1 (Orafti), the percentage of lesion was significantly lower compared with the control group $(P<0.01)$. The mean lesioned areas were 35 and $25 \%$ lower in the inulin- and Synergy1-fed groups than in the control group, respectively (Table 3 ). The representative pictures from aorta sections of the control and inulin-rich diet-fed mice are presented in Fig. 1. It is noticeable that inulin feeding results in the reduction of red-stained lipid deposits when compared with the control.

\section{Discussion}

Inulin-type fructans of various chain lengths are fermented at different parts of the large intestine, as a function of their DP, and this in turn may have different metabolic consequences. In the present study, the effect of different inulin-type fructans on atherosclerosis lesion formation in apo E-deficient mice was assessed.

The present study shows that diets containing long-chain inulin, either alone or in combination with oligofructose, significantly reduce the area of the atherosclerotic plaque in the aortic sinus when compared with control diets. All the groups studied exhibited hypercholesterolaemia. This is in agreement with the apo E-deficient mice model, in which

Table 2. Body weight, relative liver weight, caecum weight and blood pressure in male homozygous apolipoprotein E-deficient mice after 4 months on the control or inulin-type fructans-supplemented diets ${ }^{\star} \neq$

(Mean values with their standard errors for eight mice per group)

\begin{tabular}{|c|c|c|c|c|c|c|c|c|c|}
\hline & \multicolumn{2}{|c|}{ Control } & \multicolumn{2}{|c|}{ Oligofructose } & \multicolumn{2}{|c|}{ Long-chain inulin } & \multicolumn{2}{|c|}{ Synergy 1} & \multirow[b]{2}{*}{ ANOVA $(P$} \\
\hline & Mean & SE & Mean & SE & Mean & SE & Mean & SE & \\
\hline Mice weight $(g)$ & $23 \cdot 93^{\mathrm{a}}$ & 0.56 & $28 \cdot 25^{a}$ & 0.43 & $28 \cdot 27^{a}$ & 0.59 & $29 \cdot 15^{a}$ & 0.32 & NS \\
\hline Blood pressure $(\mathrm{mmHg}) \dagger$ & $110^{\mathrm{a}}$ & 4 & $112^{\mathrm{a}}$ & 2 & $108^{\mathrm{a}}$ & 2 & $112^{\mathrm{a}}$ & 3 & NS \\
\hline Relative liver weight ( $\mathrm{g} / 100 \mathrm{~g}$ body weight) & $5.99^{\mathrm{a}}$ & 0.16 & $5 \cdot 35^{\mathrm{a}}$ & $0 \cdot 10$ & $5 \cdot 65^{\mathrm{a}}$ & 0.34 & $5 \cdot 61^{\mathrm{a}}$ & 0.12 & NS \\
\hline Whole caecum weight $(\mathrm{g})$ & $0.21^{a}$ & 0.03 & $0.74^{b}$ & 0.06 & $0.62^{b}$ & 0.05 & $0.81^{b}$ & 0.07 & $<0.0001$ \\
\hline Caecum content weight $(\mathrm{g})$ & $0 \cdot 11^{a}$ & 0.01 & $0.48^{b}$ & 0.06 & $0.37^{b}$ & 0.04 & $0.53^{b}$ & 0.06 & $<0.0001$ \\
\hline
\end{tabular}

a,b Mean values within a column with unlike superscript letters were significantly different $(P<0.05)$.

* The inulin-type fructans were oligofructose, long-chain inulin or an oligofructose-enriched inulin (Synergy 1 ; for details, see p. 841 of proofs).

† Blood pressure measurement after week 15.

‡For details of diets and procedures, see p. 841. 
Table 3. Plasma and liver lipid concentrations and mean atherosclerosis lesioned area in male homozygous apolipoprotein E-deficient mice after 4 months on the control or inulin-type fructans-supplemented diets ${ }^{\star} \dagger$

(Mean values with their standard errors for eight mice per group)

\begin{tabular}{|c|c|c|c|c|c|c|c|c|c|}
\hline & \multicolumn{2}{|c|}{ Control } & \multicolumn{2}{|c|}{ Oligofructose } & \multicolumn{2}{|c|}{ Inulin } & \multicolumn{2}{|c|}{ Synergy1 } & \multirow[b]{2}{*}{ ANOVA $(P)$} \\
\hline & Mean & SE & Mean & SE & Mean & SE & Mean & SE & \\
\hline Plasma cholesterol (mmol/l) & $13 \cdot 56^{a}$ & 0.73 & $11 \cdot 55^{\mathrm{a}}$ & 0.45 & $9 \cdot 47^{\mathrm{b}}$ & 0.41 & $14 \cdot 38^{a}$ & $1 \cdot 21$ & 0.0003 \\
\hline Plasma triacylglycerol (mmol/l) & $1 \cdot 33^{a}$ & 0.15 & $0.68^{b}$ & 0.08 & $0.66^{b}$ & 0.16 & $1 \cdot 00^{\mathrm{a}, \mathrm{b}}$ & 0.17 & 0.0071 \\
\hline Hepatic cholesterol (mg/g) & $3 \cdot 19^{a}$ & 0.15 & $2 \cdot 71^{\mathrm{a}, \mathrm{b}}$ & 0.18 & $2 \cdot 45^{\mathrm{b}}$ & 0.20 & $2 \cdot 47^{\mathrm{b}}$ & 0.15 & 0.0166 \\
\hline Hepatic triacylglycerol $(\mathrm{mg} / \mathrm{g})$ & $53 \cdot 38^{a}$ & 4.97 & $27 \cdot 73^{b}$ & $4 \cdot 78$ & $20 \cdot 03^{b}$ & 2.53 & $23 \cdot 87^{b}$ & 4.86 & $<0.0001$ \\
\hline Mean atherosclerosis lesioned area (\%) & $14 \cdot 01^{\mathrm{a}}$ & $1 \cdot 14$ & $12 \cdot 44^{\mathrm{ab}}$ & 0.96 & $9 \cdot 16^{\mathrm{C}}$ & 0.77 & $10 \cdot 45^{\mathrm{bc}}$ & 1.07 & 0.0004 \\
\hline
\end{tabular}

a,b,c Mean values within a column with unlike superscript letters were significantly different $(P<0.05)$.

* The inulin-type fructans were oligofructose, long-chain inulin or an oligofructose-enriched inulin (Synergy 1 ; for details, see p. 841 of proofs).

†For details of diets and procedures, see p. 841 of proofs.

chylomicron and VLDL remnants accumulate in the blood as a result of a defect in their clearance by the liver (Meir \& Leitersdorf, 2004). Long-chain inulin lowered plasma cholesterol and TAG concentrations compared with the control group. Previous work by Mortensen et al. (2002) showed a (non-significant) tendency in low-density-receptor-knockout-deficient mice, fed inulin, to reduce the atherosclerotic process. The more potent effect of inulin in the present study could be explained by the model used, which is characterised by severe hypercholesterolaemia.

Consistent with other studies, the present data clearly support the hypocholesterolaemic (Mortensen et al. 2002) and hypotriacylglycerolaemic (Beylot, 2005) effects of inulin. This hypolipidaemic effect undoubtedly reflects reduced secretion of VLDL particles by the liver resulting from an inhibition of de novo fatty acid synthesis (Williams, 1999). Hepatic cholesterol and TAG contents are high in apo E-deficient mice compared with C57B1/6J mice (Kuipers et al. 1996; Xia et al. 2003).

Diets enriched with long-chain inulin or Synergy1 both significantly reduced hepatic cholesterol contents. It could be hypothesised that the hypocholesterolaemic effect of inulin is due, at least in part, to the fact that inulin inhibited cholesterol synthesis by propionic acid (Williams, 1999). In the present study, intake of inulin-type fructans was associated with a significant increase in the weight of the caecum in all three groups when compared with the control group. This is consistent with published data by Zdunczyk et al. (2004) demonstrating an increase in the weight of the caecum with $8 \%$ of inulin.
Indeed, inulin fermentation resulted in production of propionic acid, a major component among the SCFA products (Kim \& Shin, 1998). The decrease in hepatic TAG content by the three complex carbohydrate-rich diets is probably the result of a decrease in their synthesis (Delzenne \& Kok, 1999). This hypotriacylglycerolaemic effect could also affect the plasma cholesterol concentration because of the fact that TAG-rich particles, especially in apo E-deficient mice, are rich in cholesterol.

The pathogenesis of atherosclerosis is a complex process that depends on various factors (Tripathi et al. 2005). According to the present results, it seems that inulin reduced the atherosclerotic plaques mainly by modifying lipid metabolism. However, other mechanisms could also be involved. Busserolles et al. (2003) showed the pro-oxidative effects of sugar and that substitution of fructose by oligofructose reduced heart lipid oxidation. Thus, the substitution of simple carbohydrates for complex carbohydrates could contribute to the anti-atherogenic effect via mechanisms reducing oxidative stress. The specific action of SCFA should also be considered because they are known to modulate the expression of multiple genes involved in the pathogenesis of atherosclerosis, in addition to genes involved in lipid synthesis (Ranganna et al. 2000).

The present study demonstrates that long-chain inulin in the diet reduces the development of atherosclerotic plaque. Based on the present results, we hypothesise that inulin acts mainly by modulating lipid metabolism, but future studies will (a)

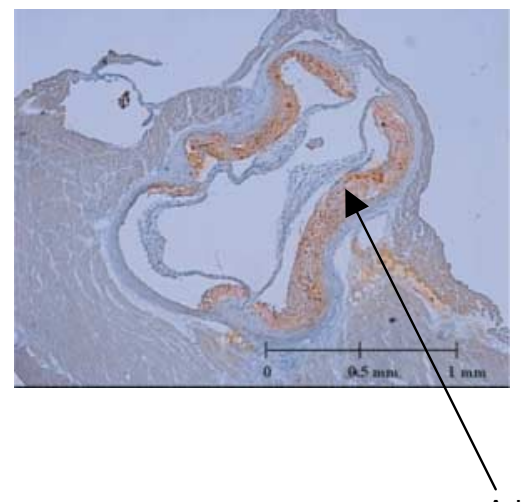

(b)

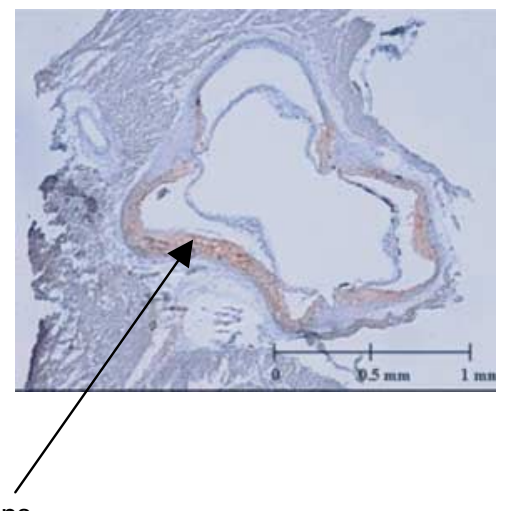

Fig. 1. Sections of aortic sinus (at $400 \mu \mathrm{m}$ ) stained by Oil red O from homozygous apo E-deficient mice fed a control sucrose-based diet (a) or an inulin-rich diet (b) for 16 weeks. For details of diets and procedures, see p. 841. 
determine the contribution of the different mechanisms to the anti-atherogenic action of inulin.

\section{Acknowledgements}

We acknowledge Claudine Lab, Séverine Thien and Dominique Bayle for their technical assistance and Jean-François Martin for statistical analyses.

\section{References}

Beylot M (2005) Effects of inulin-type fructans on lipid metabolism in man and in animal models. Br J Nutr 93, Suppl. 1, S163-S168.

Busserolles J, Gueux E, Rock E, Demigne C, Mazur A \& Rayssiguier Y (2003) Oligofructose protects against the hypertriglyceridemic and pro-oxidative effects of a high fructose diet in rats. $J$ Nutr 133, 1903-1908.

Charakida M, Tousoulis D \& Stefanadis C (2006) Early atherosclerosis in childhood: diagnostic approaches and therapeutic strategies. Int J Cardiol 109, 152-159.

Cherbut C (2002) Inulin and oligofructose in the dietary fibre concept. Br J Nutr 87, Suppl. 2, S159-S162.

Cordain L, Eaton SB, Sebastian A, Mann N, Lindeberg S, Watkins BA, O'Keefe JH \& Brand-Miller J (2005) Origins and evolution of the Western diet: health implications for the 21st century. Am J Clin Nutr 81, 341-354.

Delzenne NM \& Kok NN (1999) Biochemical basis of oligofructoseinduced hypolipidemia in animal models. $J$ Nutr 129, 1467 S-1470S.

Kaur N \& Gupta AK (2002) Applications of inulin and oligofructose in health and nutrition. J Biosci 27, 703-714.

Kim M \& Shin HK (1998) The water-soluble extract of chicory influences serum and liver lipid concentrations, cecal short-chain fatty acid concentrations and fecal lipid excretion in rats. J Nutr 128, $1731-1736$.

Kuipers F, van Ree JM, Hofker MH, Wolters H, In't Veld G, Havinga R, Vonk RJ, Princen HM \& Havekes LM (1996) Altered lipid metabolism in apolipoprotein E-deficient mice does not affect cholesterol balance across the liver. Hepatology 24, 241-247.

Mazur A, Remesy C, Gueux E, Levrat MA \& Demigne C (1990) Effects of diets rich in fermentable carbohydrates on plasma lipoprotein levels and on lipoprotein catabolism in rats. $J$ Nutr 120, $1037-1045$.

Meir KS \& Leitersdorf E (2004) Atherosclerosis in the apolipoprotein-E-deficient mouse: a decade of progress. Arterioscler Thromb Vasc Biol 24, 1006-1014.

Mortensen A, Poulsen M \& Frandsen H (2002) Effect of a longchained fructan Raftiline HP on blood lipids and spontaneous atherosclerosis in low density receptor knockout mice. Nutr Res 22, 473-480.

Napoli C, Palinski W, Di Minno G \& D’Armiento FP (2000) Determination of atherogenesis in apolipoprotein E-knockout mice. Nutr Metab Cardiovasc Dis 10, 209-215.

Nicoletti A, Kaveri S, Caligiuri G, Bariety J \& Hansson GK (1998) Immunoglobulin treatment reduces atherosclerosis in apo E knockout mice. J Clin Invest 102, 910-918.

Ranganna K, Yatsu FM, Hayes BE, Milton SG \& Jayakumar A (2000) Butyrate inhibits proliferation-induced proliferating cell nuclear antigen expression (PCNA) in rat vascular smooth muscle cells. Mol Cell Biochem 205, 149-161.

Roberfroid M (2005) Inulin-type Fructans: Functional Food Ingredients. Boca Raton, FL: CRC Press.

Roberfroid MB (2002) Functional foods: concepts and application to inulin and oligofructose. Br J Nutr 87, Suppl. 2, S139-S143.

Steinberg FM, Bearden MM \& Keen CL (2003) Cocoa and chocolate flavonoids: implications for cardiovascular health. J Am Diet Assoc 103, 215-223.

Tripathi YB, Singh BK, Pandey RS \& Kumar M (2005) BHUx: a patent polyherbal formulation to prevent atherosclerosis. Evid Based Complement Alternat Med 2, 217-221.

Williams CM (1999) Effects of inulin on lipid parameters in humans. J Nutr 129, 1471S-1473S.

Wouters K, Shiri-Sverdlov R, van Gorp PJ, van Bilsen M \& Hofker MH (2005) Understanding hyperlipidemia and atherosclerosis: lessons from genetically modified apoe and ldlr mice. Clin Chem Lab Med 43, 470-479.

Wu H, Dwyer KM, Fan Z, Shircore A, Fan J \& Dwyer JH (2003) Dietary fiber and progression of atherosclerosis: the Los Angeles Atherosclerosis Study. Am J Clin Nutr 78, 1085-1091.

Xia M, Ling WH, Ma J, Kitts DD \& Zawistowski J (2003) Supplementation of diets with the black rice pigment fraction attenuates atherosclerotic plaque formation in apolipoprotein $\mathrm{E}$ deficient mice. J Nutr 133, 744-751.

Zdunczyk Z, Juskiewicz J, Wroblewska M \& Krol B (2004) Physiological effects of lactulose and inulin in the caecum of rats. Arch Anim Nutr 58, 89-98. 